\title{
BIOTECNOLOGÍA Y ETNOMEDICINA PARA EL DESARROLLO HUMANO
}

Ruth Salinas ${ }^{1}$ Margarita García ${ }^{2}$ Aurora Velásquez ${ }^{3}$

Recibido:05/09/2013 Aceptado: 27/03/2015

\section{Resumen}

La biotecnología es la tecnología basada en la biología, especialmente usada en agricultura, farmacia, ciencia de los alimentos, medio ambiente y medicina.

La etnomedicina es una especialidad de la antropología médica que estudia las medicina tradicional, especialmente las que carecen de fuentes escritas, con énfasis en los aspectos culturales, más que en los biomédicos.

En este ensayo de análisis bibliográfico, encontramos que la etnomedicina está siendo utilizada y transformada por la biotecnología, ya que muchas plantas medicinales que están siendo procesadas en los laboratorios para luego ser fabricadas en masas y extenderlas a la población.

El problema es que algunas plantas y medicamentos están siendo patentados y desde ese momento cualquier país, que posea la planta, ya no tiene derecho a producir productos de dicha planta usando la misma tecnología. Esta situación impacta en especial a los del tercer mundo, que es donde se encuentran una biodiversidad de este tipo de plantas. En este punto se une la biotecnología con la etnomedicina, pero por desgracia también surge la biopiratería.

Palabras claves: Biotecnología, Etnomedicina, Biopiratería, Bioética, El Salvador.

1 Dra. en Medicina, Docente titular de la Universidad Evangélica de El Salvador, ruthsalinas1705@yahoo.com

2 Químico-farmacéutico del Hospital de Maternidad, del Ministerio de Salud de El Salvador MINSAL.

3 Ginecóloga-Obstetra del Hospital de Maternidad, del Ministerio de Salud de El Salvador MINSAL. 


\section{Introducción}

Tanto la biotecnología como la etnomedicina han sido aplicadas desde tiempos antiguos, en los que ni si quiera se conocían con estos nombres. A través del tiempo ambas ciencias han venido evolucionando y creciendo al mismo tiempo, al punto que en la actualidad ambos tópicos están tomando mucha importancia y se encuentran en la cumbre de su popularidad. Esto se ve ligado a un cambio de amplia magnitud en la sociedad y por consiguiente, su desarrollo, en los cuales todos estamos involucrados.

La biotecnología, en la actualidad, es un tipo de investigación científica, con aplicación tecnológica, en la cual se experimenta con cuerpos vivos, plantas y animales, incluyendo humanos, Esta rama científica ha adquirido mayor dinamismo y no cesan de aparecer nuevos retos al conocimiento y por consiguiente, nuevas propuestas éticas.

Por otra parte, la etnomedicina, proporciona conocimiento más empírico, pero en la actualidad la etnomedicina y la biotecnología se unen para dar nuevos conocimientos y utilidades a la sociedad.

\section{Biotecnología}

\section{Biotecnología: definición y evolución}

La biotecnología ha sido utilizada por el hombre desde los comienzos de la historia en actividades tales como la preparación del pan y bebidas alcohólicas o el mejoramiento de cultivos. Procesos como la producción de cerveza, vino, queso y yogurt implican el uso de bacterias o levaduras con el fin de convertir un producto natural como la leche, en un producto de fermentación más apetecible como el yogurt. En general se puede definir como el uso de organismos vivos o de compuestos obtenidos de organismos vivos para obtener productos de valor para el hombre. ${ }^{1}$

Actualmente, la Biotecnología ha evolucionado y comprende una variedad de técnicas derivadas de la investigación en biología celular y molecular, las cuales pueden ser utilizadas en cualquier industria que utilice microorganismos, células vegetales o animales. Es así que la Unión Europea la designa como la rama de la ciencia que se ocupa de las técnicas que emplean o causan cambios orgánicos en el material biológico, microorganismos, plantas y animales o que originan cambios en un material orgánico por procedimiento. ${ }^{1}$

Otros autores también dicen que a biotecnología es la aplicación comercial de organismos vivos o sus productos, la cual involucra la manipulación deliberada de sus moléculas de DNA. Por tanto, podemos decir que la biotecnología abarca desde la biotecnología tradicional, por ejemplo la fermentación de alimentos, incluso la biotecnología moderna, basada en la utilización de las nuevas técnicas del DNA recombinante (ingeniería genética), los anticuerpos monoclonales y los nuevos métodos de cultivo de células y tejidos.

\section{Clasificación}

La biotecnología puede ser clasificada en cinco amplias áreas:

Biotecnología animal: está dirigida a sistemas diagnósticos, nuevas vacunas y drogas, fertilización de embriones in vitro, hormonas de crecimiento, y otros. Los animales transgénicos han sido muy útiles para estudios de enfermedades humanas. ${ }^{2}$

Biotecnología industrial: tecnología con ADN, hace uso industrial de 
microorganismos con aplicaciones como la producción de vacunas recombinantes y medicinas, tales como insulina, hormonas, interferón, enzimas y proteínas especiales. ${ }^{3}$ Además, amino acidos y vitaminas usadas principalmente en la alimentación animal.

Biotecnología ambiental: aplicación de procesos biológicos modernos para la protección y restauración de la calidad del ambiente. Actualmente, su principal aplicación es limpiar la polución. ${ }^{2}$ La biorremediación (uso de sistemas biológicos para la reducción de la polución del aire y sistemas acuáticos-terrestres) se está enfocando en el suelo y residuos sólidos, tratamientos de aguas domésticas, industriales, procesadas y de consumo humano, aire y gases de desecho. ${ }^{4}$

Biotecnología vegetal: produce plantas con características mejoradas, con tolerancia a condiciones adversas, resistencia a herbicidas específicos, control de plagas, cultivos durante todo el año. Problemas de enfermedades y control de malezas ahora pueden ser tratados genéticamente en vez de utilizar químicos. ${ }^{2}$

Biotecnología humana: a través de un pequeño fragmento de $A D N$ se puede determinar relaciones familiares en litigios de paternidad, donantes de órganos, unir sospechosos con la evidencia de ADN en la escena del crimen (biotecnología forense). ${ }^{3}$ Con técnicas de secuenciación de ADN también se puede diagnosticar infecciones víricas, bacterianas o mapear la localización específica de los genes. ${ }^{5}$

\section{Campos de aplicación}

Existen ciertas áreas específicas donde se aplica la biotecnología, mencionadas anteriormente, entonces, dependiendo del área donde esta sea aplicada así recibe un color, para lo cual se describen a continuación:

Biotecnología roja: se aplica a la utilización de biotecnología en procesos médicos, por ejemplo, diseño de organismos para producir antibióticos, vacunas más seguras, diagnósticos moleculares y desarrollo de la ingeniería genética, entre otros. ${ }^{6}$

Biotecnología blanca: también llamada biotecnología industrial, es la que se aplicada a procesos industriales, por ejemplo, diseño de microorganismos para producir químicos, uso de enzimas, para producir productos químicos valiosos y destruir contaminantes químicos peligrosos (por ejemplo las oxidorreductasas). ${ }^{6}$

Biotecnología verde: biotecnología aplicada a procesos agrícolas. Un ejemplo de ello es el diseño de plantas transgénicas capaces de crecer en condiciones ambientales desfavorables o plantas resistentes a plagas y enfermedades. ${ }^{7}$

Biotecnología azul: también llamada biotecnología marina, describe las aplicaciones de la biotecnología en ambientes marinos y acuáticos. ${ }^{8}$

Biotecnología Dorada: aplicada a los desarrollos y procesos bioinformáticos. Es la aplicación de métodos informáticos y de computación en el análisis de datos experimentales y simulación de los sistemas biológicos. ${ }^{9}$

Biotecnología morada o violeta: se engloban las medidas de seguridad, la legislación y los valores y principios ético-morales establecidos por la sociedad en materias y aplicaciones biotecnológicas. ${ }^{9}$ 


\section{Estado Actual}

Básicamente la Biotecnología ha evolucionado a pasos agigantados y en la actualidad se están desarrollando investigaciones innovadoras y algunas hasta increíbles debido a la complejidad con que estas se están desarrollando. Dentro de algunos de los avances que se están desarrollando podemos mencionar:

- Estudios del ADN (Ácido Desoxirribonucleico) /ARN (Ácido Ribonucleico) aplicada a la genómica, fármaco-genética, sondas de genes, ingeniería genética, secuenciado, síntesis y amplificación de ADN/ARN, patrones de expresión genética. ${ }^{10}$

- Estudios del ARN de interferencia, secuenciación, ingeniería de proteínas y péptidos, moléculas grandes con acción farmacológica, identificación de receptores celulares y de señales celulares. ${ }^{10}$

- Cultivo e ingeniería celular y de tejidos, hibridación y fusión celular, vacunas y estimulantes de inmunidad, manipulación de embriones. ${ }^{10}$

- Genes y vectores de ADN/ARN, como la terapia génica, vectores virales.

- Bioinformática, como la construcción de bases de datos de genomas, secuencias de proteínas y modelización de procesos biológicos, como la biología de sistemas. ${ }^{10}$

- Nanobiotecnología, se aplican herramientas y procesos de nano y microfabricación a la construcción de dispositivos para estudiar biosistemas y aplicaciones en drogas, diagnósticos, entre otros. ${ }^{11}$

Es importante mencionar que Muñoz, en 1998, expresó que la Biotecnología tiene una relación con la economía de "carácter horizontal", lo cual se debe a que los objetivos de la biotecnología abarcan todos y cada uno de los sectores tradicionales en que se divide la actividad económica, primario secundario y terciario. Por lo cual los países se encuentran interesados en esta nueva forma de economía. ${ }^{12}$

La captación de la renta tecnológica, necesita de un proceso de obtención y producción por lo tanto las empresas "creadoras" deben de tener la capacidad de realizar todo un proceso de desarrollo tecnológico y de producción y con ésta, todas las implicaciones de mercadeo que conlleva, "para dar respuesta a las regulaciones y el manejo de los canales comerciales del producto hasta llegar al consumidor". ${ }^{13}$ La meta de llegar al consumidor es el más importante para algunas instituciones, debido a los ingresos que les genera. Esto dice que la sociedad está involucrada directamente con la biotecnología y por consiguiente con el desarrollo y avance de la sociedad.

\section{Implicaciones éticas}

Estamos viviendo en una sociedad tecnocientífica y se dice que coincide con "un momento de profundo cambio" debido a los movimientos críticos como las iniciativas Ciencia, Tecnología y Sociedad (CTS). ${ }^{12}$ Estas iniciativas surgieron en los Estados Unidos, como "reflejo de la preocupación social ante las dudas que suscita el mito de los beneficios continuos del progreso científico y tecnológico". ${ }^{12}$ En base a esto, las universidades norteamericanas establecen programas docentes e investigadores con apoyo de las agencias públicas norteamericanas implicadas en la financiación de los proyectos, menciona Muñoz. ${ }^{12}$ A partir de este fenómeno, la National Science Foundation decidió 
establecer líneas de financiación, con el fin de mantener la importancia de la Ética y los Valores en el desarrollo científico y técnico.

En la actualidad se ha llegado a argumentar que las nuevas tecnologías ofrecen variadas gamas para mejorar el nivel de vida, "entre las que se destacan las visiones que omiten la perspectiva de la existencia corporal, denominadas pos humanas: mundos clónicos, biónicos o digitales" ${ }^{14}$

En este artículo es importante definir el término Bioética para poder comprender por completo en qué momento se relaciona la biotecnología y la bioética, por lo tanto bioética tiene como definición: "ética de la vida entendida en sentido amplio, que comprende no sólo los actos del hombre sobre la vida humana, sino también sobre aquella animal y medioambiental". ${ }^{15}$

También cabe definir el término Medicina de Conveniencia ya que hace alusión a lo que se quiere pero no a lo que es necesario, lo que lleva a "la utilización de técnicas biomédicas, con otros fines diferentes a los terapéuticos, esencialmente estéticos. Este término se toma en un doble sentido, sea en relación a la apariencia corporal determinada por las imágenes sociales y culturales, o como la preferencia o escogencia individual y subjetiva, en últimas, un asunto de gusto personal". ${ }^{16}$

Existen muchas técnicas y productos innovadores y prometedores en la medicina, logrando mejorar tratamientos y a la vez se logra el objetivo de la medicina: curar, prolongar y dar una mejor calidad de vida al paciente. Aunque debemos recordar que todo esto tiene repercusiones y aquí entra la bioética, regulando cualquier situación que perjudique la integridad de los seres humanos, animales y medio ambiente.
Hay que tomar en cuenta que "los límites de la intervención biomédica sobre el cuerpo lindan con fronteras borrosas sobre el deseo y la necesidad, fortalecida esta nueva situación por las exigencias que las personas, basadas en su autonomía y su propia comprensión de la salud, hacen al médico y a los sistemas de salud". ${ }^{14}$ Estas fronteras terminan formando paradigmas biomédicos y de aquí surge la importancia de las medicinas alternativas, así como otras visiones acerca de lo que es conveniente o saludable para las comunidades.

\section{ETNOMEDICINA}

\section{Etnomedicina: definición y evolución}

Desde tiempos antiguos la etnomedicina se practica como alternativa de la medicina tradicional, en la actualidad ha cobrado mucha relevancia, por lo tanto se ha buscado una definición a través de la cual se reúnen las características de ésta. Entonces se define como el conjunto de las técnicas y saberes que, transmitidos de forma tradicional, se utilizan para la prevención y curación de enfermedades.

El antropólogo de la salud, Peter Brown, en 1998, define etnomedicina como la medicina propia de un grupo y de una cultura ya que los sistemas terapéuticos se construyen de acuerdo con las características culturales.. Si varían las culturas, variarán también las maneras de entender salud/ enfermedad, las formas de abordar los problemas y las propuestas de soluciones. ${ }^{17}$

La Medicina popular o "Folk medicine" incorpora los conocimientos médicos de los siglos pasados con las prácticas tradicionales de las poblaciones indígenas. ${ }^{18}$ El estudio de las teorías populares sobre enfermedades 
abarca creencias acerca de las causas de las enfermedades, los remedios tradicionales y las técnicas de curación, la clasificación popular y sus efectos sociales. ${ }^{19}$

La antropología médica, es la rama de la etnomedicina, que ha tratado de estudiar y explicar las creencias y prácticas médicas en culturas indígenas o tradicionales al margen de la medicina moderna, desde sus orígenes en la cultura chamánica en Asia y América Indígena, hasta las medicinas tradicionales como la medicina china, la etnomedicina mapuche, la etnomedicina mexicana, y otros. ${ }^{20}$

Según autores como Peter Brown, la sociedad occidental ha desarrollado la medicina occidental, convencional, científica y tecnológica, constituyéndose como una etnomedicina más, la cual abandona lo tradicional $^{21}$ contradiciendo a dicho sistema terapéutico, que dice que la naturaleza está íntimamente ligada a la tradición.

Es importante destacar que entre los sinónimos de la etnomedicina se encuentran: Medicina popular, Medicina folclórica, Folk medicine, etc. Estos conceptos implican tradiciones médicas que se han transmitido de generación en generación de modo no formal o académico (tradición oral). ${ }^{22}$

Otros conceptos que están relacionados pero que no coinciden en su totalidad son los de chamanismo y curanderismo, que identifican la actividad curativa ejercida por personas cuyos saberes no pertenecen exactamente a la tradición del pueblo común, sino a una tradición por lo general especializada, restringida a pocas personas e incluso secreta. ${ }^{23}$

\section{Campos de aplicación}

Debido a la naturaleza de la etnomedicina se pueden distinguir tres niveles que a continuación se describen:

a) Base de intervención médica: responde a principios de efectividad empírica. La etnomedicina de muchos pueblos, pese a estar imbuida de creencias religiosas, mágicas o supersticiosas, dispone, en ocasiones, de un sólido trasfondo racional y científico, basado principalmente en observaciones, descripciones, experimentaciones e intervenciones adecuadas para las distintas enfermedades. Las escuelas médicas tradicionales son muy organizadas y efectivas, con unos conocimientos de farmacopea $y$ técnicas de intervención física y quirúrgica muy desarrolladas. Charles H. Hugues, en 1968, ya afirmaba que casi la mitad de la farmacopea de las sociedades primitivas tiene efectos terapéuticos reales sobre las enfermedades a las que se aplican. Además es bien sabido que pueblos de la antigüedad que alcanzaron un elevado nivel de civilización, como los egipcios y los griegos, llegaron a desarrollar sistemas médicos de carácter empírico que mágicoreligioso-supersticioso. ${ }^{24}$

b) Contexto ritual y etnográfico: se rige por principios mágico-religiosos. Los rituales acompañan las intervenciones etnomédicas, se basan en la sugestión (especialmente a través de la ingestión de placebos, hipnosis y otras técnicas psicosomáticas): utilización de oraciones y en salmos (lo que se llama "curación por la palabra"), gesticulación ritual o mímica, coreografía o música. ${ }^{24}$

\section{c) Etnomedicina, religión y superstición:} Todas las religiones engloban conocimientos y prácticas relativas a la curación de las enfermedades, quienes son capaces de realizarlas, a través de milagros o de poderes mágicos, son dioses personificados, santos mediadores, sacerdotes, personas justas o chamanes y curanderos imbuidos 


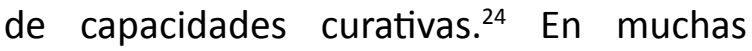
ocasiones, las creencias de tipo religioso cristiano se mezclan o contaminan con otras de carácter evidentemente mágico-pagano, por ejemplo, las creencias y la curación del mal de ojo, que se suele relacionarse con fenómenos de brujería o de hechicería. ${ }^{23}$

\section{Estado Actual}

Actualmente, la etnomedicina busca restituir la relación entre el conocimiento popular y el científico de la enfermedad y la salud, convirtiéndose, así, en un puente entre la biología y la cultura. Además forma parte importante de algunas sociedades en países en vías de desarrollo, pues se encuentra casi al mismo nivel que la medicina moderna en cuanto a preferencias. Este último aspecto se debe a la gran efectividad que tienela medicina alternativa para curar algunas enfermedades sin la necesidad de intervenciones como medicamentos o cirugías. ${ }^{17}$

Se ha visto en los últimos 70 años, surge mayor interés en el recurso natural e incrementado su utilización. ${ }^{24}$ Con base a esto, la Organización Mundial de la Salud (OMS) describe lo siguiente en relación al uso y aplicación de la etnomedicina: ${ }^{25}$

- Países asiáticos y africanos, el $80 \%$ de la población depende de la medicina tradicional para recibir atención primaria de salud.

- De las distintas formas de medicina tradicional, la más lucrativa es la medicina herbaria, que genera miles de millones de dólares de ingresos.

-Descubrimiento y aislamiento de la artemisinina a partir de Artemisia annua L., planta utilizada en China desde hace casi 2000 años, sirvió para obtener nuevos fármacos antipalúdicos.
- La existencia en los mercados internacionales de productos herbarios falsificados, de mala calidad o adulterados.

-Más de 100 países tienen reglamentada la medicina herbaria.

Como es evidente la etnomedicina está siendo muy aceptada de manera que hasta la OMS hace sus declaraciones a favor de este tipo de medicina, pero es tan grande su aceptación que a tal punto que ha surgido, a través de la biotecnología, la biopiratería que se ha vuelto un problema muy grande. El término de biopiratería fue ideado en 1993 por Pat Mooney, quien refiere que "[...] la utilización de los sistemas de propiedad intelectual para legitimar la propiedad y el control exclusivos de conocimientos y recursos biológicos sin reconocimiento, recompensa o protección de las contribuciones de las comunidades indígenas y campesinas, por lo que la bioprospección no se puede ver más que como biopiratería". ${ }^{26}$

\section{Implicaciones éticas}

La etnomedicina no queda exenta de las implicaciones éticas, por lo tanto la OMS expresa su posición ante la medicina tradicional, a través de la declaración de Beijín, en el año 2008, la cual dice:

"La medicina tradicional es un recurso precioso que necesita ser respetado y apoyado como un valor a tomar en cuenta en avances terapéuticos y el descubrimiento de nuevas clases de medicamentos". ${ }^{25}$ "La investigación y desarrollo en medicina tradicional es parte de la estrategia global de OMS y del plan de acción en salud pública, innovación y propiedad intelectual adoptado por la Asamblea Mundial de la Salud". ${ }^{25}$ En este apartado, la OMS aprueba 
la medicina tradicional como una alternativa para el tratamiento de enfermedades. Cabe mencionar que la OMS se refiere a la medicina tradicional como una forma nueva forma de innovar.

\section{Conclusiones}

Cuando se habla de Biotecnología y Etnomedicina se pueden considerar como dos líneas paralelas que tienen en común el uso de elementos que se encuentran en la naturaleza con la diferencia que la etnomedicina hace uso de plantas y animales para tratar o aliviar problemas de salud basándose en el conocimiento o tradición popular de una determinada cultura; por su parte la biotecnología igual toma elementos de la naturaleza pero es aquí donde se aplican los conocimientos científicos en diversas aéreas de tal manera que se ha llegado hasta el punto de la manipulación del material genético.

Se puede decir que la etnomedicina, tenía menos influencia económica, que la biotecnología, por lo que algunas instituciones no invertían este campo, pero eso no quiso decir que no se realizaban investigaciones en este ámbito. En la actualidad se está utilizando a la etnomedicina para crear la biotecnología lo cual ha permitido el descubrimiento de compuestos bioactivos en plantas con beneficios importantes para la nutrición y la salud.

Desafortunadamente existen personas que están haciendo contrabando de semillas o plantas medicinales. Por ejemplo, en una tribu de la India se encontró una planta con propiedades adelgazantes, la tribu solo recibe el $0.003 \%$ de las ganancias de las ventas de esta planta biotecnologizada, por lo tanto muchos países han tenido que registrar sus plantas. En el caso de Brasil se dice que ha registrado 5,000 plantas para que no llegue a ser patentadas. ${ }^{27}$

La salud humana es una necesidad básica, y la vida de las personas, se requieren de medidas urgentes y audaces que no permiten esperar leyes o regulaciones de medicamentos, además del alto costo con el que se puedan conseguir y lo cual los vuelve inaccesibles a la mayoría de la población, aquí toma importancia la etnomedicina y se puede recurrir a este tipo de medicina genérica para poder salvar vidas y para proporcionar a la población una vida más digna. ${ }^{27}$

Para concluir es evidente que existe una relación directa entre la biotecnología y la etnomedicina. La primera se alimenta de la segunda. En este sentido, hay que resguardar la manipulación, destrucción y saqueo de los conocimientos y recursos que pertenecen a las culturas de los pueblos en vías de desarrollo.

El desarrollo y aplicación desenfrenado de la biotecnología, puede causar deterioro de la biodiversidad de muchos países. Los recursos utilizados para este desarrollo, son protegidos mediante derechos de propiedad exclusiva, pero a menudo quienes los protegen son las grandes industrias quienes se ven beneficiadas por lo cual no llegan hasta los verdaderos propietarios, es decir, los países de origen. ${ }^{28}$ Esto vuelve urgente la implementación de marcos legales efectivos que protejan la biodiversidad de estos pueblos. No se trata de impedir el avance de la biotecnología sino más bien de regularla para que se convierta en herramienta de beneficio a la humanidad y no un instrumento de destrucción de la misma.

Tanto la biotecnología como la etnomedicina pueden ayudar a revolucionar la medicina 
tradicional, pero todo esto implica que no debemos dejar de hacer investigación y que por lo tanto realicemos investigaciones de este tipo para que seamos parte de ese cambio y que a la vez generemos nuevos conocimientos para estas ciencias. Además, enseñar a las nuevas generaciones como explotar esasáreas y dejarles el conocimiento que tanto les servirá para crear un cambio mejor en este mundo.

\section{Fuentes consultadas}

1. Dunner S. Limitaciones a la Biotecnologia. Mundo ganadero. 1994; 5(2): p. 43-45.

2. Falck-Zepeda, Falconi, Sampaio-Amstalden J, Solleiro Rebolledo L, Trigo, Verástegui. La biotecnología agropecuaria en America Latina. Mayo 2009.

3. Noguera NG. Portaley. [Online].; 2005 [cited 2012 Octubre 12]. Available from: http://www. portaley.com/biotecnologia/bio4.shtml.

4. Sánchez Martín J, Rodríguez Gallego J. Biorremediación: fundamentos y aspectos microbiológicos. Industria y Minería. Marzo 2003; 351; p. 12-16.

5. Duque JP. Biotecnología: Panorámica de un sector. In La Coruña, editor. España: NETBIBLO; 2010. p. 109 págs.

6. Avalos Gutiérrez I. Biotecnología e industria: un ensayo de interpretación teórica. Unica edición. Flury $V$, Gutiérrez $M$, editors. San José: Orton Instituto Interamericano para la Agricultura/ CATIE; 1990.

7. Castillo Rodríguez $\mathrm{F}$, otros y. Biotecnología ambiental. Única edición. Madrid: Editorial TEBAR, S. L.; 2005.

8. Universidad San Carlos III. La Biotecnología y su aplicación Industrial. Única edición. Modrego A, López Carrascosa, editors. Madrid: R. B. Servicios Editoriales, S. A.; 1994.
9. Canarias Bioregión. Canarias Bioregión. [Online].; 2010 [cited 2012 Octubre 10]. Available from: http://www.canariasbioregion. org $/$ ? $\bmod =$ Areas \& titulo=Biotecnologia Dorada\&cat $=40$.

10. Trigo E, Traxler G, Pray E, Echeverría G. Biotecnología agrícola y desarrollo rural en América Latina y el Caribe: Implicaciones para el financiamiento del BID. Serie de documentos técnicos del Banco Interamericano de Desarrollo. 12 Enero 2000.

11. Correa CM. Biotecnología: Innovación y producción en América Latina. Universidad de Buenos Aires, editor. Buenos aires; 1996.

12. Muñoz E. Nuevas tecnologías y el diálogo entre sociedad e industria: el caso de la biotecnología. Madrid: Instituto de Estudios Sociales Avanzados; 1998. Report No.: Documento de Trabajo 98-14.

13. Bisang R. De la biotecnología a la producción. In CEPAL. Biotecnología y desarrollo. Santiago de Chile: Naciones Unidas; 2009. p. 11-16.

14. Escobar Triana J. Bioética, cuerpo humano, biotecnología y medicina del deseo. Revista Colombiana de Bioética. 2007 enero-junio; 2(1): p. 33-51.

15. Postigo Solana. Bioéticaweb. [Online].; 2006 [cited 2012 Septiembre 25]. Available from: http://www.bioeticaweb.com/concepto-debioactica-y-corrientes-actuales/.

16. Hottois G. Nouvelle encyclopédie de bioéthique: médecine, environnement, biotechnologie. 1st ed. Hottois, Missa JN, editors.: De Boeck Supérieur; 2001.

17. Mena AA. El temazcal en la cultura tradicional de salud y en la etnomedicina mesoamericana. Gazeta de Antropologia. 2006 Abril; 22(6).

18. Pollak-Eltz A. La Medicina Popular en Venezuela. 1st ed. Venezuela: Academia Nacional de la Historia; 1987. 
19. Gil Yepez C. Introducción a la medicina antropológica Estudantil OdB, editor. Texas: mprenta Universitaria. Universidad Central de Venezuela; 2009.

20. Gubler R. El papel del curandero y la medicina tradicional en Yucatan. Red de Revistas Científicas de América Latina, el Caribe, España y Portugal. 1996; 6 (12): p. 11-18.

21. Pérez Lugo. Consideraciones para el estudio del binomio salud-enfermedad en la cultura popular. Revista de Ciencias Sociales. 2009 Diciembre; 15(4): p. 708-715.

22. Arteaga Cabrera W. Etnohistoria, Etnomedicina e Historia de la Medicina. Archivos bolivianos de historia de la medicina. 1999 Junio; 5(1): p. 15-20.

23. Pedrosa JM. El conjuro de la rosa: poesía, magia y medicina popular en España y América. Revista de historia de la medicina y de la ciencia. 1993; 45(2): p. 127-142.
24. Salgado ER. Plantas Medicinales de la Amazonia Peruana: Estudio de su uso y cultivo. Iquitos: Instituto de Investigaciones de la Amazonía Peruana ; 1997. Report No.: ISBN 9972-667-03-0.

25. OMS. World Health Organization. [Online].: OMS;2008 [cited 2012Septiembre28]. Available from: http://www.who.int/medicines/areas/ traditional/TRM_BeijingDeclarationSP.pdf.

26. Delgado GC. La Biopirateria y la propiedad intelectual como fundamento del desarrollo biotecnológico. Revista Latinoamericana de Economia. 2001; 32(126): p. 175.

27. CICODE. "bioética y biotecnología para el mundo en vías de desarrollo". 2009. Video.

28. Massieu Y. Acceso a recursos biológicos y biopiratería en Mexico. El cotidiano. 2002 Julio; 19(114): p. 72-87. 